\title{
Lesson study for students with intellectual disability
}

\author{
Kamilla Klefbeck \\ Faculty of Education, Kristianstad University, Kristianstad, Sweden and \\ Faculty of Education, Malmö Universitet, Malmo, Sweden
}

\begin{abstract}
Purpose - This study aim was to analyze how lesson study can enhance learning for students with intellectual disability, and how teachers' collaboration affects the design and analysis of the intervention.

Design/methodology/approach - Lesson study was used as a methodological framework. Ten special educational needs teachers met the researcher for three collaborative meetings. Between meetings, teachers performed and adjusted a lesson on a particular mathematical issue: quantity and size judgment. To evaluate the lesson design, students completed pre- and post-lesson examinations and attitude tests with Likert-type scales.

Findings - Students' knowledge increased during the study. The mean scores for the first group (six students) were 4.3 in the pre-test and 6.5 in the post-test (effect size 0.9). For the second group (four students), the mean score was 3.8 in the pre-test and 4.3 in the post-test (effect size 0.2). Attitude measurement showed split opinions; seven students had a positive experience and three had a predominantly negative experience. Assessment of teacher certainty using transcribed audio recordings of teachers' statements during the collaborative meetings indicated a positive relation between teacher expressions of certainty and student learning. The teacher-researcher collaboration increased teachers' focus on student learning and deepened the researcher's analysis.
\end{abstract}

Originality/value - There is an urgent need to explore collaborative development in special educational needs teaching. Lesson study is an effective way of examining teachers' collaborative processes using data on teachers' reasoning about teaching and students' learning.

Keywords Lesson study, Intellectual disability, Special educational needs teaching, Collaborative meetings, Mathematics, Professional certainty

Paper type Research paper

\section{Introduction}

In Sweden, students with intellectual disability are enrolled in a compulsory special educational system, known as compulsory schooling for students with intellectual disability. This segregated school system has been criticized by the Swedish Schools Inspectorate (Swedish School Inpectorate, 2010) for focusing on social, emotional and health issues at the expense of students' academic learning. Hedegaard-Sørensen and Langager (2012) have emphasized that special educational need (SEN) teaching requires a continuum of didactic

(C) Kamilla Klefbeck. Published by Emerald Publishing Limited. This article is published under the Creative Commons Attribution (CC BY 4.0) licence. Anyone may reproduce, distribute, translate and create derivative works of this article (for both commercial \& non-commercial purposes), subject to full attribution to the original publication and authors. The full terms of this licence may be seen at http:// creativecommons.org/licences/by/4.0/legalcode.

This study is part of the Swedish National Research School, Special Education for Teacher Educators (SET) project, funded in the entire research process from study design to submission, by the Swedish Research Council (grant no. 2017-06039), for which I am grateful. I extend my sincere thanks to my supervisors professors: Mona Holmqvist and Lotta Andersson at Malmö University (Sweden), AnnLouise Ljungblad at Gothenburg University (Sweden) and Jonas Aspelin at Kristianstad University (Sweden). Ialso thank Diane Williams, PhD, from Edanz Group (www.edanzediting.com/ac), for editing a draft of this manuscript.

Declaration of conflicting interests: The author declares no potential conflicts of interest with respect to the research, authorship or publication of this article.

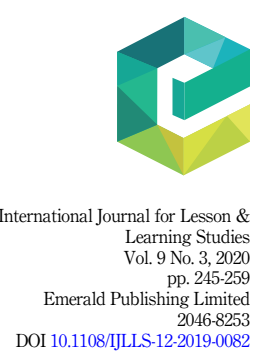

Received 13 December 2019 
IJLLS 9,3

dimensions, as both relational and social aspects are considered part of the teaching. This statement corresponds with Ernest's (2019) emphasis on the ethical aspect of teachers' responsibility to do their very best in teaching, as enhanced prerequisites for learning are crucial for SEN students' life chances (Ernest, 2019).

\subsection{Teacher competence and experience of teaching challenges}

Teachers' professional competence can be defined as knowledge, understanding and skills capabilities, including the competence to teach students with complex educational needs (Caena, 2011). Munthe (2003a) uses the concept "professional certainty," measured on a scale from certain to uncertain, to estimate challenges that teachers experience in actions and decisions. Munthe suggests a positive relation between teachers' perceived professional certainty and students' expectation of individual teaching instructions. This relationship has been examined by Ernest (2019), who stated that students' capabilities depend on teachers' beliefs. To contextualize the connection between human thought and behavior, Bourdieu's concept of habitus can be used to express the determined patterns that preserve and carry forward existing expectations. In relation to this process, Mayrhofer (2019) suggests that an approach of collaborative development may enable teachers to increase their ability to deal with unpredictable situations.

Participating in lesson study can enhance teachers' expectations of students' learning opportunities, as observing lessons can reveal previously unrecognized abilities (Dudley, 2013). The databases Eric and PsycINFO were searched to identify lesson study research on students with intellectual disability (keywords: "intellectual disability" and "lesson study"). The search produced no hits. The closest studies found focused on Jiritsu-Katsudo (Utsumi and Ando, 2019), a collaborative approach customized for students with physical or intellectual disabilities. As teachers often experience uncertainty when teaching students with physical and intellectual disability, collaborative teaching may be useful (Utsumi and Ando, 2019).

\subsection{Lesson study versus improvement science in education}

The method of lesson study was developed in the Japanese school system, in which teachers work collaboratively to develop classroom teaching through a process of observations, feedback and collective planning (Isoda, 2007). Lesson study originally focused mainly on mathematics (Isoda, 2007), a focus preserved in this study, which aimed to propose a mathematical learning objective (or object of learning) in the initialization phase. The model has several similarities to improvement science and plan-do-study-act cycles (Langley et al., 2009; Lewis, 2015).

\subsection{Teachers' awareness of students' learning}

Lesson study can be useful to help teachers identify and collaboratively interpret evidence of students' learning. It can also help them to decide where to go next (Norwich et al., 2014). These benefits were identified in Klefbeck's (2020) systematic review of educational approaches to enhance communication skills for learners with a combination of intellectual disability and autism spectrum disorders. Regardless of the educational approach used, educators' awareness and responsiveness seem to be preconditions for learners' abilities to take advantage of different ways to communicate, such as linguistic gestures (Baker-Ramos, 2017), physical tools (Hughes et al., 2011; Hamilton and Snell, 1993) and video self-modeling (Hart and Whalon, 2012). 


\subsection{Aim and research questions}

The study aim was to analyze how lesson study can be used to enhance learning for students with intellectual disability, and how teacher collaboration affects the design and analysis of the intervention. The following research questions were explored:

$R Q 1$. How does implementation of a lesson study cycle influence both learning for students with intellectual disability and professional certainty experiences for SEN teachers?

RQ2. What are the advantages and limitations of teacher-researcher collaborative research?

RQ3. How do teacher evaluations of student attitudes and learning outcomes correlate with researcher assessment of participating teachers' expressions of professional certainty when facing diverse student groups with intellectual disability?

\section{Theoretical standpoints}

\subsection{Variation theory}

A broad interpretation of variation theory (Holmqvist Olander and Nyberg, 2014; Ling Lo, 2012; Marton, 2015) was used to provide teachers with tools to visualize students' learning from multiple perspectives. Variation theory explains how different ways of perceiving and conceptualizing situations and phenomena in the environment opens the mind and makes learning possible (Marton, 2015). In variation theory, the concept of a learning objective (or an "object of learning") is essential to target students' learning. According to variation theory, different ways of organizing learning are tools that enhance learning. Kullberg et al. (2017) illustrate variation theory using the example of the conceptual understanding of a triangle; the learner must compare the triangle with circles or rectangles to distinguish its uniqueness. However, to organize teaching, the act of learning has to start with the question of what is to be learnt (Marton, 2015). Here, the object of learning in the lesson study was identified by participating teachers during their initial meeting. The lesson design was based on various theoretical assumptions, and the prepared material provided opportunities for learners to discern specific aspects of the content.

\subsection{Teachers' professional certainty in actions and decisions}

A broad interpretation of Munthe's (2003a) construct of professional teacher certainty was used for analysis. However, instead of measuring teachers' perceptions of their own certainty, researcher interpretations of teachers' expressions of certainty in actions and decisionmaking during collaborative discussions were used. These expressions cannot be equated with professional competence, but Munthe's research (2003a) showed that teacher abilities to cope with the ongoing process of decision-making enable the process of teaching. In this study, the interpretation of degrees of professional certainty is associated with Bornemark's (2018) concept of "not knowing." According to Bornemark, although knowledge is presumed, there are always unique and challenging situations, so seeking knowledge involves coming as close as possible to the area that is unknown.

\section{Methods}

\subsection{Unit of analysis}

This study used a mathematical context, on the assumption that mathematics poses particular challenges when teaching students with intellectual disability. The unit of analysis was the initialization phase of a series of iterative research cycles (e.g. audio-recorded
Lesson study for students 
IJLLS 9,3

\section{8}

planning meetings) and pre- and post-tests of student knowledge. The overall intention was to investigate how a lesson study approach affects teachers' abilities to empower students with intellectual disability to actively interact and reflect on their own learning.

\subsection{Ethics}

All participating students had an intellectual disability diagnosis, so it was considered particularly important to meet the Swedish Research Council's ethical guidelines (Vetenskapsrådet, 2017). Only participants who provided informed consent participated. The selection process and methods used are described in the ethical approval documents agreed by the Swedish Ethical Review Board (2019-02,767).

\subsection{Participants}

Cooperation was sought from school leaders and SEN teachers who were willing to participate. Using convenience sampling (Loseke, 2012), a municipal school in a small Swedish town was selected. In this school, students with intellectual disability are educated in separate classrooms but in close collaboration with regular schooling. Practical considerations directed this choice, including the researcher's travel arrangements, and the ethical requirement that the researcher should have no personal knowledge of the school, teachers or students.

\subsection{Teacher group}

The collaborative group comprised ten SEN teachers. The school leader required all the teachers in the team to participate, so the researcher had to abandon Marton's (2015) proposal of having three to six participants in a lesson study cycle. All participating teachers had substantial teaching experience (ten years or more), including 3-31 years of SEN teaching. The teachers were aged 40-65 years; all teachers but one were women. All teachers had passed a teacher examination; half had passed a SEN teaching examination. For the study, all participating teachers were defined as SEN teachers, owing to the nature of their teaching experience. All teachers were invited to participate in the collaborative discussions; unfortunately, one to three teachers were absent from each meeting. Four teachers participated in the first research lesson (one as a performing teacher and three as observers) and four in the second research lesson (one participated as a performing teacher, one as a teacher assistant and two as observers.)

\subsection{Student group}

The student group comprised ten students with mild-to-moderate intellectual disability aged between 12-16 years (four girls, six boys). After students' regular group division, they were divided into two groups for the research lessons, coded as group 100 (first research lesson) and group 200 (second research lesson). Group 100 contained six students, three of whom were girls. Group 200 contained four students, all of whom were boys.

\subsection{Design}

The main challenge in research focusing improvements of existing teaching is the gap between researchers' ideas of an optimal study and the practical considerations faced in the field. Fixsen and Ogden (2014) highlight this problem when describing implementation science directing enhancements in teaching or social service, seldom includes longitudinal and systematically collected data from large populations, but usually features pilot studies presenting preliminary findings. As population size and duration were problems in the present study (Fixsen and Ogden, 2014), additional assessments were included to ensure 
validation. Hence, a multiphase approach was used. Specifically, in this context of intellectually challenged student learning, the lesson study was evaluated from dual perspectives: both teachers' professional certainty and students' attitudes and learning were measured.

Teachers' professional certainty was measured qualitatively using a descriptive approach (Potter, 2003), interpreting central themes from transcriptions of audio recordings of teachers' collaborative discussions. In this process, Munthe's construct (2003a) was used to define teachers' expressions, ranging from uncertain to certain. The categorization of themes, and particularly didactical, practical and relational certainty, relied on Munthe's (2001) variable groupings. A theme was categorized as didactical if it expressed questions about reaching academic goals, practical if it described methods to intervene or organize teaching and relational when it was about building relationships between students and parents (Munthe, 2001). A mixed-methods approach (Creswell, 2014) was used, in which the didactical, practical and relational themes were categorized and quantified as they appeared in the qualitatively pre-analyzed data.

The researcher interpreted teachers' expressions of uncertainty and certainty in their actions and decisions during the first and second meeting by linking relevant expressions to study themes. Internal validity (Loseke, 2012) was assessed by sharing interpretations of teachers' expressions in the first and second collaborative meeting as feedback to teachers during the last collaborative meeting. During this final meeting, all participating teachers were given opportunities to reflect on the researcher's preliminary findings.

Students' perceived difficulty and level of joy were measured using a five-point Likerttype scale (Jamieson, 2004) with a combination of words and symbols. The scale was designed in collaboration with participating teachers to ensure students' understanding.

3.6.1 Design of the learning material. In line with variation theory (Marton, 2015), the students received a complete measurement kit that permitted comparison of the differences in measuring spoons (Figure 1). This enabled them to understand size based on a representation of different sizes. They also measured different substances: solids and liquids, water and macaroni. This meant they encountered variation in representations of quantity differences independently of substance type. They also had to pour contents into a liter measure to check the amount with two different representations of measures. Finally, in line with variation theory, they learnt about measurement differences by keeping the quantity (e.g. 2) invariant, but varying the measure used (e.g. comparing two teaspoons with two deciliters).

\subsection{Procedure for lesson study cycle as a research instrument}

Munthe et al. 's (2015) model of lesson study was used. Teachers and researcher worked together to define a learning gap with an explicit object of learning (Marton, 2015). The process is shown in Figure 2.

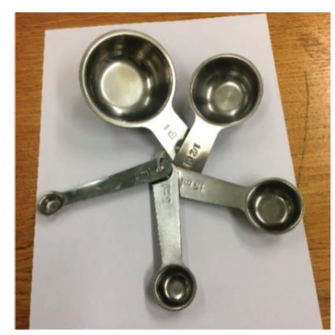

In line with variation theory, students should be able to differentiate the sizes of the parts of the measurement kit, noticing the difference between, for example, half a tablespoon and half a deciliter. They should be guided to discern differences in the size of the measures. This can be achieved by comparing differences in the quantity measured by half of each spoon, as the amounts will differ.

Figure 1. The measurement kit 


\section{IJLLS \\ 9,3}

3.7.1 Data collection. Students' performance was measured both quantitatively by pre-and post-tests and qualitatively by observation by teachers. Pre- and post-tests and the attitude test were constructed during the collaborative meetings. It was considered important to measure students' attitudes to determine the views of the students involved (UNICEF, 2009). The collaborative meetings (a total of $7 \mathrm{~h}$ and $45 \mathrm{~min}$ ) were audio taped and transcribed verbatim. These data also captured teachers' expressions of their certainty twice during the study to assess their attitudes.

\section{Results: implementation of the lesson study}

As the implementation of lesson study in the context of SEN teachers' design of lessons for students with intellectual disability is central to the present research context, the stages of the lesson study cycle are described in detail as follows:

\subsection{Step 1 - collaborative planning}

4.1.1 Basic data. Nine teachers participated in the first collaborative meeting (one was absent). The meeting lasted $2 \mathrm{~h}$.

4.1.2 Identify a learning gap. The teachers and the researcher jointly identified a learning gap regarding students' prerequisites to develop mathematical thinking. During the meeting, the researcher provided all teachers with the opportunity to share their reflections. The gap identified concerned reasonableness and mathematical concepts. One teacher stated, Now, when you talk about reasonableness, I think of concrete situations existing in the classroom, conversations and conflicts between the students, for example, related to what an exclusive car costs.

During the session, one teacher defined the mutual object of learning:

... when 6th to 9th grade students have "home and consumer studies," they keep asking which measure to use. The students ask when to use the larger one and when to use the smaller one. This really is problematic, because many of the students use "little" and "a lot" in reverse. They might take half a tablespoon, when there should be half a milliliter. They do not seem to understand that there is a difference; they just see that they took a half.

All teachers agreed on a lesson focusing on naming each part of the measurement kit (see Figure 1) and the relationships between size and dimension. One teacher made a clear statement about the object of learning: "It is useful, it is important in everyday life."

4.1.3 The object of learning. A shared lesson plan about mathematical concepts and the relationships between size and dimension was prepared. During the initial meeting, the teachers and researcher linked the object of learning to a mathematical context within the Swedish curriculum (Swedish National Agency for Education, 2018) for students with intellectual disability. The syllabus states that all students should be given the opportunity to reflect in a mathematical context and should also be given the opportunity to learn to use subject-specific words, concepts and symbols (Swedish National Agency for Education, 2018). The intention was to design the lesson to be as concrete and comprehensible as possible, so it was planned for a session on home and consumer studies.

4.1.4 Design of the lesson plan. During the collaborative discussions, the teachers assumed that the opportunity for peer reflection would enable student learning. Hence, they designed a

Figure 2.

The lesson study cycle

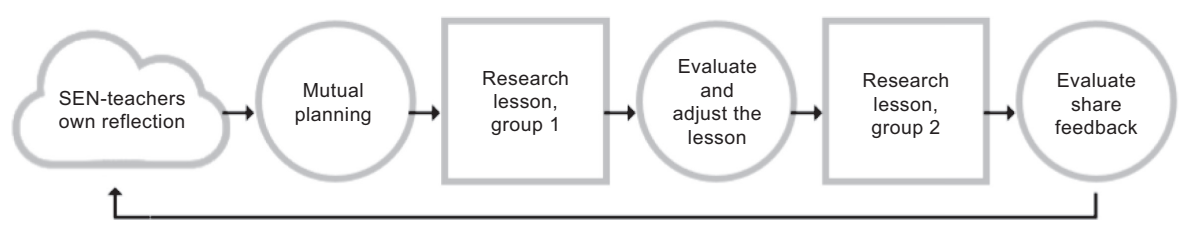


lesson plan involving the students working in pairs. The lesson plan included solving tasks focused on measurements of different sizes and dimensions. For instance, the students were required to measure different amounts with the measurement tools and define the size and dimension of different kitchen items. Teachers had different ideas about how they could best enable students' learning. For example, one teacher thought that verbal feedback at each step was a prerequisite for learning. Another felt that students might benefit from a certain amount of hesitation, to provide a chance for reasoning that would enhance their learning. Finally, teachers collaboratively solved the question of feedback through a lesson design with elements of self-correcting work.

4.1.5 Pre-tests, post-tests and attitude measurement. The researcher instructed teachers to design a knowledge test based on the mutually decided object of learning (the relationship between size and dimension). The teachers decided to use a measurement kit and a set of cards with the names of each spoon in the kit. Each correct answer would get one point, with a maximum of seven correct answers. The plan was to ask the students verbally to match the prewritten cards with the correct spoon in the measurement kit. In the last part of the test, students would be verbally asked to identify the biggest and smallest spoons and the results would be photographed. To minimize the risk that students would learn the arrangement of the spoons, all spoons were to be rearranged between the pre- and post-tests.

The researcher also asked teachers to develop an evaluation tool to measure students' experiences of participating in the lesson. Initially, teachers suggested using Mentimeter presentation software or images on an iPad, but finally agreed on pre-printed pictures of facial expressions. The teachers ensured that the symbols used were familiar to the students (Table 1 shows the test planning stages).

\subsection{Step 2 - conduct first research lesson (group 100)}

4.2.1 Basic data. One teacher conducted the lesson for six students, and three teachers participated as observers. Table 2 shows basic participant information and the outcome of the pre-test, post-test and attitude test.

The attitude test indicated that most students felt that the post-test was just as difficult as the pre-test. It also showed that most students appreciated the lesson. However, one student (102) stated that the lesson had been boring. Nevertheless, the pre- and post-tests for this student showed that her knowledge had improved after the lesson.

\subsection{Step 3 - collaborative evaluation and adjustment of lesson design}

4.3.1 Basic data. Seven teachers participated in the second collaborative meeting (three teachers were absent). The meeting lasted $1 \mathrm{~h}$ and $45 \mathrm{~min}$.

4.3.2 Evaluation of students' learning. One observer reported that her first impression was that the object of learning had been too difficult for one of the students (105). This student had walked around and muttered to himself during the first part of the lesson. However, the teacher had later observed that this student appeared to handle the situation and seemed to

Step Instruction

1 Add correct note to each unit in the measurement set

$2 \quad$ Lay out the notes for biggest and smallest by the correct unit in the measurement set

3 Easy-difficult attitude test on paper. This was easy/difficult, make a cross by the expression that corresponds with your experience (picture of five faces, showing feelings in scale from happy to sad)

4 Boring-joyful attitude test on paper. This was boring/joyful, make a cross by the expression that corresponds to your experience (picture of five faces, showing feelings in scale from sad to happy)
Lesson study for students 


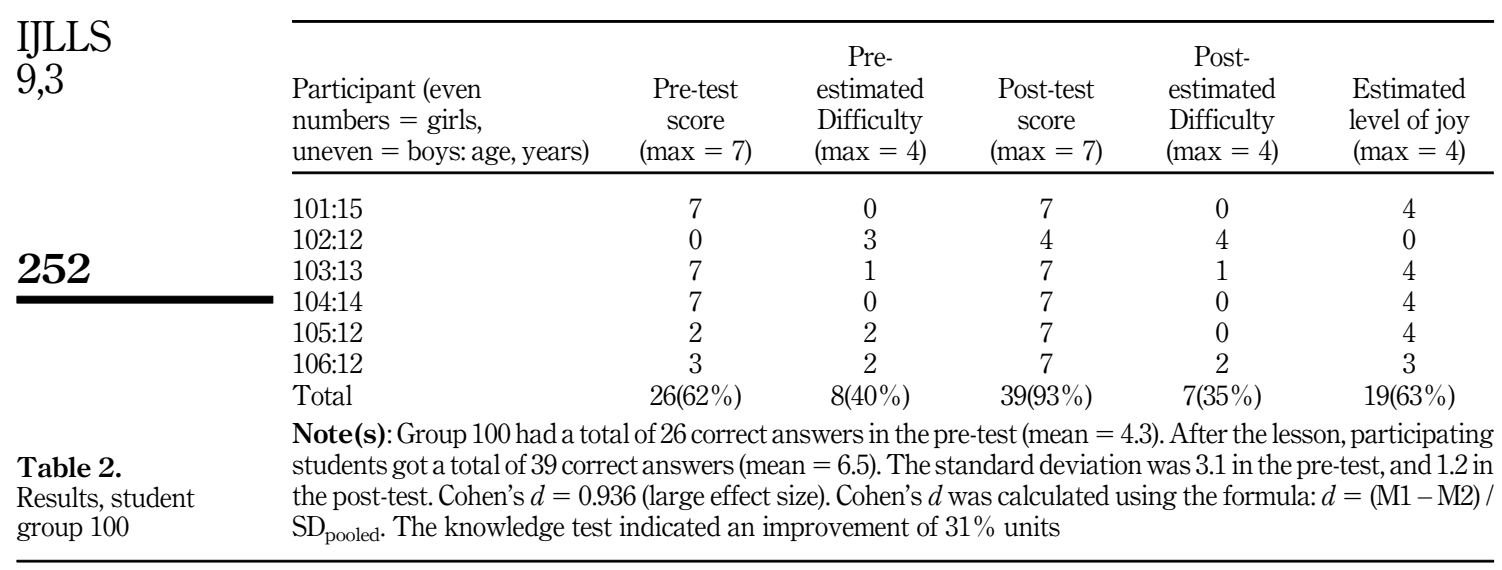

gain knowledge from the lesson. The observer reported that the act of learning seemed to become visible during the teacher's verbal instructions, because the student suddenly said aloud, "I have made a mistake." He had realized that he had been wrong in one part of the pretest. This student's results in the pre- and post-test showed that his results were the most improved in the group. The teachers' discussions about this student's learning showed how their comparisons of the same didactical episode expressed both their own perspectives and the students' learning.

4.3.3 Evaluation of the attitude tests. The attitude test results corresponded with the observer notes, but one answer surprised the observers. One student (104) had verbally complained that the lesson was ridiculous and far too easy (this student answered all questions in the test correctly), but in the attitude test, she marked the happiest face.

4.3.4 Adjustments. The teacher who taught the lesson commented that the students had not wanted to work in pairs, as planned, but that this did not cause any problems as the students still helped each other at critical moments. She decided to let this pass. During the meeting, the teachers therefore decided to change the instruction to work in pairs to a suggestion. An adjustment was made based on one step in the lesson, as the observers had noticed that the carton that was partly filled with macaroni had caused some students problems, because it had been difficult for them to get the macaroni out of the box. Instead, it was decided that the macaroni should be poured from a bowl. When the teachers adjusted the lesson plan, there was a brief discussion about whether all participating students could read. After a brief hesitation, one teacher stated that all the students could read, so no adjustment was made for this purpose. Instead, an organizational adjustment was made as the collaborative discussion had revealed a need for an extra teacher to assist, because the teacher in the first lesson had experienced some difficulties when on her own. The teachers predicted this difficulty might increase in the next student group. The discussion revealed comparatively lower expectations of the next student group's capacity to learn.

\subsection{Step 4 - the second research lesson (group 200)}

4.4.1 Basic data. One teacher conducted the lesson for four students, one acted as an assistant and two teachers participated as observers. Table 3 shows basic participant information and the outcome of the pre-test, post-test and attitude test.

The attitude test showed that all students considered the test easy, both before and after the lesson. The attitude test indicated divided opinions, as two students marked the most positive 


\begin{tabular}{|c|c|c|c|c|c|c|}
\hline $\begin{array}{l}\text { Participant (even } \\
\text { numbers = girls, } \\
\text { uneven = boys: age, years) }\end{array}$ & $\begin{array}{l}\text { Pre-test } \\
\text { score } \\
(\max =7)\end{array}$ & $\begin{array}{l}\text { Pre- } \\
\text { estimated } \\
\text { Difficulty } \\
(\max =4)\end{array}$ & $\begin{array}{l}\text { Post-test } \\
\text { score } \\
(\max =7)\end{array}$ & $\begin{array}{l}\text { Post- } \\
\text { estimated } \\
\text { Difficulty } \\
(\max =4)\end{array}$ & $\begin{array}{c}\text { Estimated } \\
\text { level of joy } \\
(\max =4)\end{array}$ & $\begin{array}{l}\text { Lesson study } \\
\text { for students }\end{array}$ \\
\hline 201:12 & 4 & 0 & 3 & 0 & 0 & \\
\hline $202: 13$ & 2 & 0 & 4 & 0 & 4 & \\
\hline $205: 12$ & 2 & 0 & 4 & 0 & 0 & 253 \\
\hline $207: 15$ & 7 & 0 & 7 & 0 & 4 & \\
\hline Total & $15(54 \%)$ & $0(0 \%)$ & $17(61 \%)$ & $0(0 \%)$ & $8(50 \%)$ & \\
\hline \multicolumn{7}{|c|}{$\begin{array}{l}\text { Note(s): Group } 200 \text { had a total of } 15 \text { correct answers in the pre-test (mean }=3.8 \text {. After the lesson, participating } \\
\text { students got a total of } 17 \text { correct answers (mean }=4.3) \text {. The standard deviation was } 2.4 \text { in the pre-test and } 1.9 \text { in } \\
\text { the post-test. Cohen's } d=0.231 \text { (trivial effect size). Cohen's } d \text { was calculated using the formula: } d=(\mathrm{M} 1-\mathrm{M} 2) / \\
\mathrm{SD}_{\text {pooled. }} \text {. The knowledge test indicated an improvement of } 7 \% \text { units }\end{array}$} \\
\hline
\end{tabular}

option and two the most negative. However, this may have been unrepresentative, because one observer reported that one student (205) had changed his answer from the second most joyful alternative (3) to the least joyful (0) after glancing at another student's (201) sheet.

\subsection{Step 5 - evaluation and feedback}

4.5.1 Basic data. Nine teachers participated in the third collaborative meeting (one was absent). The meeting lasted $2 \mathrm{~h}$.

4.5.2 Evaluation of the lesson plan and students' learning. Teachers had substantially different views of the nature of the students' collaboration in the second lesson. Both teachers and observers agreed that the students had completed the tasks in pairs (201 and 205; 203 and 207), but they had different views about whether working in pairs could really be interpreted as working collaboratively. For example, one observer described how students 203 and 207 had not distributed the tasks fairly. One student (207) had completed all the steps and the other (203) had just commented when he thought things had gone wrong. The observer stated, “. . . those corrections could no't possibly pass as cooperation, as the students had been rude to each other." Another teacher replied, "I did not hear their discussion, but from a distance it looked like collaboration."

Analysis of the test scores indicated that the student who had commented rather than doing the work (203) had a lower pre-test score than his partner (207), but showed some improvement in the post-test.

During the meeting, the teachers examined pre-test and post-test scores and found that there had been progress, although it was not as clear as in the first lesson. One teacher reflected, "If a student has better results in the post-test, does it really indicate increased knowledge?"

The performing teacher said that her expectations of this student group's negative attitudes had been accurate. One observer pointed out that this was only partly true, because one student (205) had changed his answer in the attitude test at the last minute after looking at his classmate's response. Critical views emerged about the test design, because it seemed that one student might have failed to read the test sheets in the knowledge test.

\section{Results: summary}

\subsection{Implementation of the lesson study cycle, students'learning and teachers' expressions of certainty}

The first research question concerned how implementation of a lesson study cycle can influence learning for students with intellectual disability and how the approach influences teachers' expressions of professional certainty. 


\section{IJLLS \\ 9,3}

254

5.1.1 Students' learning. Table 4 shows performances in student group 100 compared with performance in student group 200. The effect size showed that the first research lesson had a stronger effect than the second. The difference between the pre-test and post-test indicated lower knowledge improvements in group 200 than in group 100, perhaps because of lack of sufficient adaptation, or because the learning content was too difficult for these students. It is also possible that teacher expectations were comparatively lower for group 200. Jamieson's (2004) advice to interpret Likert-type scale findings as ordinal levels of measurement were followed in interpreting the attitude test results. Hence, the findings were not measured quantitatively, but from an individual perspective.

The results implied that lesson study positively may affect learning for students with intellectual disability, in this process the analysis of the collaborative discussions revealed the importance of adapting the difficulty level to each student.

5.1.2 Teachers' professional certainty. Comments in the first collaborative meeting related most frequently to the didactical theme $(n=23)$, closely followed by the practical theme $(n=18)$. Comments on relational issues were less common $(n=4)$. Analysis of the themes on a scale from professional uncertainty to certainty showed that teachers' expressions were slightly more likely to be uncertain than certain when related to the didactical theme (13 vs 10), and considerably more likely to be certain than uncertain when considering practical issues (17 vs 1 ). Very few expressions were relational, but slightly more were linked to certainty than to uncertainty (3 vs 1 ).

Teachers' expressions about their actions and decisions during the second collaborative meeting were again predominantly linked to the didactical theme than to the practical and relational themes. Teachers' expressions were more uncertain than certain on didactical issues (7 vs 2), and slightly more certain than uncertain on practical issues (2 vs 1 ). Only one expression was linked to relational certainty. Teachers' professional certainty was not always easy to measure, because statements expressing didactical uncertainty could also contain insight and knowledge about students. For example, one teacher expressed uncertainty during the discussion of how the lesson could best be designed, because students' knowledge can be difficult to determine.

During the final meeting, teachers viewed the researcher's preliminary analysis of expressions of their professional certainty from the first and second collaborative meetings. All teachers had the opportunity to reply to these preliminary findings. Below are four different teachers' comments:

(1) Teachers working with students with intellectual disability probably experience more didactical uncertainty compared with other teachers.

(2) We experience challenges every day.

(3) Our mission is complicated because our didactical prerequisites change every day, as these students' learning abilities are not fixed.

(4) I think even the relational perspective is demanding, because working with students with intellectual disability means that you have to give part of yourself in teaching.

Table 4.

Comparison between

student groups

\begin{tabular}{lccccc}
\hline Group & Pre-test mean & SD & Post-test mean & SD & Effect size \\
\hline 100 & 4.3 & 3.1 & $6.5(+1.2 / 28 \%)$ & 1.2 & 0.936 \\
200 & 3.8 & 2.4 & $4.3(+0.5 / 13 \%)$ & 1.9 & 0.231
\end{tabular}




\subsection{Advantages and limitations}

The second research question was about the advantages and limitations of using a teacherresearcher collaborative research approach.

5.3.1 Advantages. In the simultaneous roles of researcher and facilitator, the researcher tried to ensure that all crucial decisions, such as the object of learning, the lesson plan and the pre- and post-tests were designed collaboratively by the teachers, which strengthens teachers' active participation. In this process, Munthe et al. 's (2015) well-defined instructions for lesson study helped the researcher's collaboration with the teachers. The use of pre- and post-tests made it easier to focus on the object of learning during the collaborative intervention. Teachers' comments during the last meeting showed that they appreciated the opportunity to scrutinize crucial aspects of their teaching.

As Ernest (2019) has suggested, teachers' ability to reflect on teaching is fundamental, because self-evaluation helps them to avoid the risk of failing to update their beliefs about their students' capacity.

5.3.2 Limitations. One limitation of this study was the large number of participating teachers. The loss of teachers between meetings also created uncertainty in the collaboration. Having ten teachers is far from Marton's (2015) ideal model of three to six participating teachers. The data showed that not all teachers participated in every meeting. The audio recordings showed that this was a problem, as some teachers missed the opportunity to influence the collaborative process. During the second meeting, one teacher asked if some students were unable to read, a question answered by another teacher. During the second lesson (group 200), one student appeared to have difficulty decoding text, and the observers felt that this had limited this student's ability to succeed. The fact that the teachers had neglected the expressed concerns about one student's limited reading abilities suggested that teachers were not confident in the collaboration. This reflects Munthe's (2003b) assumed links between teachers' expressions of professional certainty and their preparedness for individualizing the teaching environment.

Additional limitations were considered due to the researcher's perspective. The researcher did not participate as an observer in the lesson study cycle and was unable to video the lessons. This made it harder to follow up important moments during the teachers' collaborative discussions. The distance between the researcher and the process of learning reflects Takahashi and McDougal's (2016) concerns about lesson study. They found that its use outside Japan, especially by researchers lacking personal experience of the technique, seldom achieved the dual intentions of enhanced professional development and student learning. Hence, both researchers and teachers need to expand their experience of lesson study as it is more important to gain new knowledge than to improve a flawless lesson (Takahashi and McDougal, 2016).

\subsection{Students' attitudes and learning versus teachers' expressions of certainty}

The third research question was in what way teachers' evaluation of students' attitudes and learning outcomes correlates with researcher assessment of participating teachers' expressions of professional certainty when facing diverse student groups with intellectual disability. The measured effect size was consistent with teachers' expressions of certainty in decisions and actions when planning the first and second lessons. This association became clear, as didactical certainty was comparatively stronger when teachers collaboratively planned the degree of learning challenges for the first group's lesson than when they planned the degree of learning challenges for the second group.

During the last collaborative meeting, a discussion arose concerning surprising findings on the attitude tests. One teacher said that it had been exciting to evaluate the attitude test results, because some students that the teachers thought had disliked the lesson had actually 
IJLLS 9,3

marked the joyfullest faces. This highlights the difficulties teachers experience in understanding what interests students and how to design lessons to extend their knowledge.

\section{Discussion}

In this section, the results are assessed in relation to the study aims, implications for practice are given, and finally acknowledges and considerations for further research are given.

\subsection{Lesson study as a vehicle for educational research}

This study aimed to explore how lesson study can be used to enhance learning for students with intellectual disability and how teacher collaboration affects the design and analysis of the intervention. The results suggest that students were overstretched in some areas and under challenged in others. This corresponds with Dudley's (2013) findings that participating in lesson study can reveal previously unknown student abilities to observing teachers.

To further improve students' learning, the researcher could have been more proactive in stopping the discussions and directing teachers' attention to the most challenging subjects, such as the discussion about one student's ability to decode text. Muthe (2003) construct is a useful way of measuring expressions of professional certainty, particularly given the range and complexity of SEN teachers' assignments. However, the findings also indicated that teachers' expressions of uncertainty could be considered essential for identifying crucial aspects of student learning (e.g. if students' pre-linguistic text decoding includes conceptual understanding). The findings suggested that the association between expressions of professional certainty and students' prerequisites for learning may be less obvious in SEN teaching, which answers the research question.

Using a lesson study approach, participating teachers' expressions of uncertainty can be considered a vehicle for future change and development instead of a solid measure of the correct way to act. This corresponds to Bornemark's (2018) concept of "not knowing" as a presumption of knowing. This is exemplified by the responses given by teachers regarding their experience of participating in lesson study. One teacher said that the intervention had given her a unique opportunity to reflect on specific teaching sequences. Another teacher expressed doubts about the macaroni box discussion, stating, "How can a discussion about measuring macaroni from a cardboard box be defined as research?"

\subsection{Implications for practice}

This work has several implications for practice:

Attitude tests, in combination with structured observations of student performance, can reveal unexpected information about students' experiences of teaching. In group 100 this was exemplified when one of the students complained about the ridiculous lesson, which contradicted with the attitude test, marking the most joyful alternative. In group 200, the performing teacher expressed doubts about the students' willingness to participate in the lesson, which was questioned through the attitude test, as two of four students, marked more joy, than sorrow.

Using a collaborative approach in which teachers compare their experiences of the same didactical episode can make teachers' perspectives more visible. In present study, measured expressions of professional didactical uncertainty suggest a strategic use of collaborative reflection could strengthen professional proficiency in teaching students with intellectual disability.

SEN teachers' expectations can affect students' prerequisites for learning. This can have both positive and negative effects. In group 100, one of the observers perceived the object of learning as too difficult for one of the students, but the post lesson test revealed this student 
improved the most, which indicates higher expectations positively affect students' learning. In second research lesson, one of the student's inability to read was unnoticed, which probably hindered this student's prerequisite skills.

\subsection{Validity}

To avoid the criticism that implementation science seldom features a sufficient population size and duration (Fixsen and Ogden, 2014), a multiphase approach was implemented from dual perspectives to measure students' learning and teachers' experiences of professional challenges. The discussions during the lesson study cycle facilitated the researcher's interpretation of professional certainty, as teachers had to focus on challenging aspects of student learning. Providing teachers with opportunities for feedback on the preliminary analysis strengthened the findings and were a form of internal validity check (Loseke, 2012). The iterative process of responding to the preliminary findings about professional certainty achieved a balanced interpretation characterized by a reciprocal process of give and take.

\subsection{Considerations for further research}

In future research, observation protocols should be supplemented with video recordings. This will enable both researchers and teachers to participate in the discussions. The use of video may provide additional opportunities for the design of the pre- and post-tests, because concrete learning events can be evaluated. These may be very useful in teaching students with intellectual disability, as it is important to make the object of learning discernible in teaching (Marton, 2015). Without video-recorded lessons, it was difficult to distinguish which aspects to highlight.

Having ten participating teachers was not ideal for giving teachers the opportunity to deal with unpredictable situations (Mayrhofer, 2019); smaller samples would be more useful in future studies. The use of student case studies instead of student groups should also be explored (Dudley, 2013; Kuno and Ikura, 2014) to measure student learning, as students with intellectual disability are a strongly heterogeneous group.

\section{References}

Baker-Ramos, L.K. (2017), "Gesture and signing in support of expressive language development", Inquiry in Education, Vol. 9 No. 2, article 2, available at: https://digitalcommons.nl.edu/ie/vol9/ iss $2 / 2 /$.

Bornemark, J. (2018), “The limits of ratio: an analysis of NPM in Sweden using Nicholas of Cusa's understanding of reason", in Ajana, B. (Ed.), Metric Culture: Ontologies of Self-Tracking Practices, Emerald Publishing, Bingley, pp. 235-253.

Caena, F. (2011), "Education and training 2020 thematic working group professional development of teachers", Teachers' Core Competences: Requirements and Development (2011).

Creswell, J.W. (2014), A Concise Introduction to Mixed Methods Research, Sage Publications, Thousand Oaks, California.

Dudley, P. (2013), "Teacher learning in Lesson Study: what interaction-level discourse analysis revealed about how teachers utilized imagination, tacit knowledge of teaching and fresh evidence of pupils learning, to develop practice knowledge and so enhance their pupils' learning", Teaching and Teacher Education, Vol. 34, pp. 107-121.

Ernest, P. (2019), "The ethical obligations of the mathematics teacher", Journal of Pedagogical Research, Vol. 3 No. 1, pp. 80-91, doi: 10.33902/JPR.2019.6.
Lesson study for students 


\section{IJLLS 9,3}

Fixsen, D.L. and Ogden, T. (2014), "Facing the challenges of implementation", Zeitschrift für Psychologie, Vol. 222 No. 1, pp. 1-3, doi: 10.1027/2151-2604/a000159.

Hamilton, B. and Snell, M. (1993), "Using the milieu approach to increase spontaneous communication book use across environments by an adolescent with autism", Augmentative and Alternative Communication, Vol. 9, No 4, pp. 259-272. doi:10.1080/07434619312331276681.

Hart, J.E. and Whalon, K.J. (2012), "Using video self-modeling via iPads to increase academic responding of an adolescent with autism spectrum disorder and intellectual disability", Education and Training in Autism and Developmental Disabilities, Vol. 47, No 4, pp. 438-446.

Hedegaard-Sørensen, L. and Langager, S. (2012), Samarbejdets kunst: arbejdsfallesskaber og samarbejdsrelationer på Specialskoler, (The Art of Collaboration: Working Communities and Collaborative Relationships at Special Schools.), Institut for Uddannelse og Pædagogik, Aarhus Universitet.

Holmqvist Olander, M. and Nyberg, E. (2014), "Learning study guided by variation theory: exemplified by children learning to halve and double whole numbers", Journal of Research in Childhood Education, Vol. 28 No. 2, pp. 238-260, doi: 10.1080/02568543.2014.884030.

Hughes, C., Golas, M., Cosgriff, J., Brigham, N., Edwards, C. and Cashen, K. (2011), "Effects of a social skills intervention among high school students with intellectual disabilities and autism and their general education peers", Research and Practice for Persons with Severe Disabilities, Vol. 36 Nos 1-2, pp. 46-61, doi:10.2511/rpsd.36.1-2.46.

Isoda, M. (2007), Japanese Lesson Study in Mathematics: Its Impact, Diversity and Potential for Educational Improvement, World Scientific, London.

Jamieson, S. (2004), "Likert scales: how to (ab) use them", Medical Education, Vol. 38 No. 12, pp. 1217-1218.

Klefbeck, K. (2020), "Educational approaches to improve communication skills of learners with autism spectrum disorder and comorbid intellectual disability: a systematic review", working paper, Malmö University, Malmö, Sweden, 20 March.

Kullberg, A., Kempe, U.R. and Marton, F. (2017), "What is made possible to learn when using the variation theory of learning in teaching mathematics?”, ZDM, Vol. 49 No. 4, pp. 559-569, doi: 10. 1007/s11858-017-0858-4.

Kuno, H. and Ikura, G. (2014), "Investigating society 'close-up': a case-study of an individual student, Yumiko, and the construction of a footbridge on Route 419", Journal of Social Science Education, Vol. 13 No. 2, pp. 87-103.

Langley, G.J., Moen, R.D., Nolan, K.M., Nolan, T.W., Norman, C.L. and Provost, L.P. (2009), The Improvement Guide: A Practical Approach to Enhancing Organizational Performance, John Wiley \& Sons, Hoboken, NJ.

Lewis, C. (2015), "What is improvement science? Do we need it in education?", Educational Researcher, Vol. 44 No. 1, pp. 54-61.

Ling Lo, M. (2012), Variation Theory and the Improvement of Teaching and Learning, Acta Universitatis Gothoburgensis, Göteborg.

Loseke, D.R. (2012), Methodological Thinking: Basic Principles of Social Research Design, Sage, London.

Marton, F. (2015), Necessary Conditions of Learning, Routledge, London.

Mayrhofer, E. (2019), "Lesson study and teachers' beliefs: how a Bourdieuian perspective could make a difference", International Journal for Lesson and Learning Studies, Vol. 8 No. 1, pp. 19-33, doi: 10.1108/IJLLS-11-2018-0091.

Munthe, E. (2001), "Measuring teacher certainty", Scandinavian Journal of Educational Research, Vol. 45 No. 3, pp. 167-181.

Munthe, E. (2003a), “Teacher's professional certainty: a survey study of Norwegian teachers' perceptions of professional certainty in relation to demographic, workplace, and classroom variables", Doctoral dissertation, Faculty of Education, University of Oslo. 
Munthe, E. (2003b), "Teachers' workplace and professional certainty", Teaching and Teacher Education, Vol. 19 No. 8, pp. 801-813, doi: 10.1016/j.tate.2003.02.002.

Muthe, E. (2003), Lesson study: $i$ utdanning og praksis (Lesson Study: In Education and Practice), Cappelen Damm akademisk, Norway, Oslo.

Norwich, B., Dudley, P. and Ylonen, A. (2014), "Using lesson study to assess pupils' learning difficulties", International Journal for Lesson and Learning Studies, Vol. 3 No. 2, pp. 192-207.

Potter, J. (2003), "Discursive psychology: between method and paradigm", Discourse and Society, Vol. 14 No. 6, pp. 783-794.

Swedish School Inpectorate (2010), Undervisningen i svenska grundsärskolan. Kvalitetsgranskning, rapport 2010:9 (Teaching in Swedish Special School. Quality Review, Report 2010: 9.), Fritzes, Stockholm, available at: https://www.skolinspektionen.se/globalassets/publikationssok/grans kningsrapporter/ kvalitetsgranskningar/2010/svenska-grundsar/01-webb-slutrapport-undervisning en-sv-grsar.pdf.

Swedish National Agency for Education (2018), Läroplan för Grundsärskolan 2011: Reviderad 2018. (Curriculum for Special School 2011: Revised 2018), Norstedts Juridik AB, Stockholm, available at: https://www.skolverket.se/undervisning/grundsarskolan/laroplanoch-kursplaner-for-grundsarskolan/laroplan-for-grundsarskolan.

Takahashi, A. and McDougal, T. (2016), "Collaborative lesson research: maximizing the impact of lesson study", ZDM, Vol. 48 No. 4, pp. 513-526.

UNICEF (2009), Barnkonventionen. FN:s konvention om barnens rättigheter. (UN Convention on the Rights of the Child.) UNICEF, Stockholm, available at: https:/www.unicef.org/sites/default/files/ 2019-04/UN-Convention-Rights-Child-text.pdf.

Utsumi, Y. and Ando, T. (2019), "Teacher needs and relevant Factors for teaching jiritsu-katsudo in special needs schools for children with physical disabilities", Journal of Special Education Research, Vol. 7 No. 2, pp. 79-88.

Vetenskapsrådet (2017), "God forskningssed (Good research practice)", available at: https://www.vr.se/ download/18.2412c5311624176023d25b05/1555332112063/God-forskningssed_VR_2017.pdf.

\section{About the author}

Kamilla Klefbeck is a member of the Faculty of Education at Malmö University and Kristianstad University, Sweden. She is a part of the Swedish National Research School Special Education for Teachers Education (SET) funded by the Swedish Research Council (grant no. 2017-06039). Kamilla Klefbeck is also a lecturer in special education at Kristianstad University. Her main research interest is in special education, primarily targeting students with intellectual disability and comorbid ASD. Her research focus on special educational needs students' active participation in education. Kamilla Klefbeck can be contacted at: kamilla.klefbeck@hkr.se
Lesson study for students

For instructions on how to order reprints of this article, please visit our website:

www.emeraldgrouppublishing.com/licensing/reprints.htm

Or contact us for further details: permissions@emeraldinsight.com 